\title{
TURKEY AND THE EUROPEAN UNION
}

\section{Hagen LCHTENBERG*}

\section{Abstract}

Turkey's relationship with the EU has blown hot and cold over the past 35 years. Whilst the relationship has enjoyed long interludes of constructive dialogue and real progress, there have been sporadic disagreements and disengagements. That there has been a great increase in Turkey - EU trade and financial co-operation over this period is in no doubt. It is in the political sphere, however, that the relationship has become strained. Of course, Turkey has a long pro - European history and enjoys excellent relations with many member states. Nevertheless, Turkey often feels excluded from the European family, sowing the seeds of doubt and scepticism in the minds of the Turkish public. Whilst Turkey has made vast political and economic progress since 1963, the EU has moved on too, maintaing a gap which becomes no easier to bridge with the passage of time. This short article attempts to summarise the progress made in Turkey - EU relations over the past 35 years and, in particular, to highlight some of the legal problems which remain before Turkey might be admitted to full membership.

\section{Introduction}

A review of the development of Turkey - EC relations over the last 35 years reveals an uncertain and diverse picture. Periods of enthusiasm and progress contrast dramatically with periods of distance, difference and stalemate. Nevertheless, beyond the political instability, an underlying trend of ever closer relations and broad- 
ening co-operation is still disclosed. The legal foundation for this trend was laid by the Association Agreement, signed in Ankara in 1963, which came into force on the 1st December 1964. On this basis, relations have slowly developed, culminating in the establishment of a Customs Union in 1995.

The EU has emerged as Turkey's most important trading partner, accounting for around $50 \%$ of all Turkish exports. Whilst EC exports to Turkey account for only $2,5 \%$ of all EC exports the growth rate in this field is dynamic; EC exports to Turkey rose by $35 \%$ in the first year of the Customs Union alone.

Beyond the export data one has to take into account the scale of EU direct investment in Turkey and the increased financial co-operation within the framework of the Association that has taken place. The full economic picture taking these factors into account discloses an increasingly intensive economic relationship.

An assessment of political devolopments is more ambivalent. On the one hand, there is an underlying pro - European sentiment, in part connected to a long tradition of close and friendly relations to some EU Member States particularly Germany. On the other hand, the relationship has been subjected to periods of cooling-off and of scepticism, which have inevitably left their impression on the current state of the political relationship.

The following observations should be regarded as an attempt to look at the facts and underlying problems of the Turkey - EU relationship. These observations are of course taken from a European, a German, perspective. Nevertheless, they also represent a personal view which includes the experience of many years dedicated to the work of the joint project on Turkey - EU Relations.

\section{The Legal Dimension}

1. The relationship between Turkey and the EC is mainly based on the Association Agreement. This agreement established regulation with a high degree of complexity. It was aimed at "establishing ever closer bonds between the Turkish people and the peoples in the EEC" and at a "joint pursuit of the ideals underlying the Treaty establishing the EEC". It also laid down that "the accesion of Turkey to the Community at a later date" was to be facilitated. Therefore, it provided for the establishment of a Customs Union through progressive stages. The framework was outlined in the Agreement itself and the Additional Protocol of 1970, which also provided the timetable for its implementation. This framework was to be expanded upon through decisions of the Council of the Association, a joint body composed of representatives from the Turkish Government, and of the Member States of the Community. The EEC - Treaty served as the model for the basic principles structuring the 
Association, including the four freedoms constituting the internal market namely, the free movement of goods, services, persons and the freedom of establishment.

2. From the date of the entering into force of the ankara Agreement, the legal bonds between Turkey and the EC were regulated by Community Law. It was the European Court of Justice in Luxembourg which decided that the Association Agreement concluded between the EC and third countries were to be regarded as subject to Community Law. Consequently, the Court secured its own jurisdiction on the interpretation of the provisions forming the Agreement and the decisions of the Association Council. But the importance of the Community Law status of the framework provisions also extended to the substantive law insofar as the general principles of Community Law apply also with respect to the application and interpretation of the inherent provisions of the Association Agreement. This was made clear in the judgments dealing with the rights of Turkish workers living and working in Member States.

Without going into details of these cases, it has to be said that classifying these provisions as 'integrating part of Community Law' ensures a much higher level of legal certainty and protection. This applies of course only to those regulations which are sufficiently clear and pecise and which do not depend on further legislation either by the Community or the Member States. The regulations in question possess direct effect.

Furthermore, it has to be understood that no individual Member State has either the competence to change these regulations unilaterally, nor is it entitled to refuse their application. Member States are bound by a requirement of solidarity in the application of Community Law.

Finally, it should always be remembered that Community Law enjoys priority over the law of the Member States and that, consequently, national law may not be applied when it is incompatible mor in conflict with Community Law.

3. Since 1995, the final stage of the Customs Union has been completed. For a wide range of commercial goods, free movement has been establisled. Regulations on coal and steel-products as well as on agricultural products have been adopted. Customs on imports and exports between Turkey and the EU and quotas on textiles from Turkey have been eliminated. The freedom of establishment and the freedom to provide services, however, still require further regulation.

Of the principles agreed in the Ankara Agreement and the Additional Protocol of 1970, the area in which most work still needs to be done is the establishment of the freedom of movement for workers. In this respect the Council of the Association has been unable to agree on the measures necessary to implement the principle laid 
down in Art. 12 of the Ankara Agreement under which the contracting parties agreed to be "guided by Arts 48,49 and 50 of the Treaty of Rome establishing the Community for the purpose of progressively securing freedom of movement for workers between them".

Notwithstanding the regulations adopted regarding the improvement of the legal situation of those Turkish workers who are already resident in Member States (by Decisons Nos. 2/76, 1/80 and 3/80), no progress has been achieved with respect to mobility between Turkey and the EC.

4. When it is considered that the Association Agreement was intended to facilitate Turkey's accesion to the Community, it has to be observed that the Agreement therefore established the closest and broadest links between the EC and any other third state outside the European economic sphere. The Agreement goes beyond the level of commitments established by the Association Agreements with the Middle and East European states. Without any doubt, it therefore constitutes a reliable and effective basis for more than 'just' co-operation; facilitating a partial integration of Turkey into the EC. Compared with full membership there are two main differences:

a) Turkey is not admitted to the full acquis communautaire and

b) Turkey is excluded from the decision-making of the EC institutions.

Therefore the question of Turkish accession remains on the table.

The Ankara Agreement includes an article dealing with full membership, Art. 28. It provides that the contracting parties will examine the possibility of Turkey's accesion to the Community as soon as it is clear through the implementation and functioning of the Agreement that Turkey is in a position to fulfill all the obligations arising from the EC - Treaty; that Turkey is capable of adopting the aquis communautaire.

The wording of this Article reveals that it does not provide a right of accesion but an obligation to examine the conditions for admission. Its spirit, however, confirms the joint position that the Association is intended to prepare Turkey for membership. The commitment to consider accession is subject to two conditions;

a) The Association Agreement has to function properly and

b) Turkey has to be able to implement the full acquis communautaire.

At present it has to be observed that from an entirely legal point of view condition a) has not yet been satisfied. Even though considerable progress has been made, the Association is not yet complete. A positive judgment on the succesful implementation and working of the Ankara Agreement is still not possible. An analysis 
of the fultilment of condition b) requires, first of all, extensive consideration of the content of the acquis communautaire. The terminus is used as a shorthand for all Community law, political declaration, programmes and decisions as well as the jurisprudence of the Court of Justice. It is clear that the application of the acquis communautaire would have a strong impact on the existing legal order in Turkey.

The necessary transfer of legislative competence to the European Institutions may require an amendment of the Turkish Constitution regarding the powers of the Parliament. A large part of Turkish law will have to be adapted to Community standards and a farreaching reorganisation of the executive and the judiciary may be necessary in order to ensure the proper implementation of Community Law in Turkey.

The problems which have to be mastered in this respect cannot be judged from an outside perspective, though one has to be aware that the acquis comunautaire is not a static bu a dynamic object. The Treaties of Maastricht and Amsterdam have added numerous new aspect to Community Law, the judgments of ECJ and legislation passed by the Council continuosly add the acquis.

5. On the other hand, Art. 28 provides a basis for a fair procedure regarding an application for accession. It specifically excludes the possibility that, in making a decision on Turkey's membership, criteria other than those found in the acquis communautaire and the economic and legal functioning of the Association Agreement could be used. Thus the discussion of whether Turkey is a 'European State' is not relevant for the accession question. The geographic dimension has been settled by the conditions of Turkey's full membership as laid down in the Association Agreement.

Secondly, the aspect which has sometimes been raised that religious and culttural differences exclude Turkey's membership cannot be considered as relevant. The cultural difference is not important, but the existence of a legal, political and economic order which is compatible with the principles upon which the Community is founded is, such as democracy, respect for human rights, the fundamental freedoms and the rule of law (Art. 6 of the Treaty of Amsterdam, amending Art. F of the Maastricht Treaty). But it is beyond any doubt that in cases where religious rules conflict with these principles Turkish state legislation has to prevail.

6. Summing up, it has to be stated that the full implementation of the Association Agreement constitutes a major step towards full membership. Association and accession are not alternative options for the relationship between Turkey and the EC, both are progressive steps towards full membership.

Furthermore, the internal legal and economic situation has to be brought as close as possible to the principles of the acquis communautaire. This is not a re- 
quirement directed against Turkey but an indispensable means by which the equal application of the fundamental principles of Community law and policy throughout the Community can be ensured.

\section{The Political Dimension}

It is not really the job of a lawyer to examine the political issues involved in Turkey - EC relations. But it is obvious that, in this context, the legal and political dimensions cannot be clearly separated from one another.

Analysis of this topic embraces both the evaluation of internal politcal situation in Turkey as well as Turkey's political environment and her relations with other Member States. The Community, drawing from both these aspects of the political dimension, adopts the position that, at present, the conditions for entering into negotiations on Turkey's accession to the Community have not been met. This was expressed in the Commission's Opinion in 1989 regarding Turkey's 1987 application for full membership and later in the Community's position in the Council of the Association in 1997.

The Community expressed, in that context, that Turkey's application would be judged according to the same conditions and criteria as in the case of the other candidate states. The European Council held at Luxembourg in 1997 finally called a European Conference with the purpose of establishing a forum for conflict management to which Turkey, Cyprus and the Eastern European states were invited. It was expressly stated that the invitees were considered to be candidates for full membership.

Furthermore, the European Council adopted a proposal for a European strategy with the purpose of facilitating Turkish accession to the Community. The principles guiding this strategy were subsequently worked out by the Commission in a paper dated 3rd March 1998 presenting the first operative proposal for a European strategy for Turkey. This paper covers a broad range of subjects; from deepening of the Customs Union, agriculture, financial assistance, harmonisation of law, technical Co-operation in human rights and humanitarian question. Nevertheless it is not surprising that these proposals could not satisfy Turkish expectations as the central issue remained open, a clear perspective for full membership.

\section{Conclusions}

Beyond understanding this disappointment, a careful assesment of the proposals and state of progress nevertheless recommends itself. In this connection, it 
has to be taken into account that, notwithstanding the economic and poltical progress in Turkey during the past few years, the gap between Turkey and the Community has remained due to continuous development within the Community itself. The closer political $\mathrm{co}$ - operation in the fields of justice and home affairs as established through the Maastricht Treaty requires more and more political homogeneity of the Member States. Inevitably, whilst this makes the goal of membership more attractive it simultaneously makes the path towards that goal more arduous.

$$
* * *
$$


